\title{
A multi-objective optimization-based pavement management decision-support system for enhancing pavement sustainability
}

\author{
João Santos ${ }^{\mathrm{a}}$, Adelino Ferreira ${ }^{\mathrm{b}, *}$, Gerardo Flintsch $^{\mathrm{c}}$ \\ a IFSTTAR, AME-EASE, Route de Bouaye, CS4, F-44341, Bouguenais, France \\ ${ }^{\mathrm{b}}$ Road Pavements Laboratory, Research Center for Territory, Transports and Environment, Department of Civil Engineering, University of Coimbra, Rua Luis Reis Santos, \\ 3030-788, Coimbra, Portugal \\ ${ }^{\mathrm{c}}$ Center for Sustainable Transportation Infrastructure, Virginia Tech Transportation Institute, The Charles Via, Jr. Department of Civil and Environmental Engineering, Virginia
} Polytechnic Institute and State University, 3500 Transportation Research Plaza, Blacksburg, VA, 24061, USA

\section{A R T I C L E I N F O}

\section{Article history:}

Received 26 January 2017

Received in revised form 9 June 2017

Accepted 5 July 2017

Available online $\mathrm{xxx}$

Keywords:

Pavement management

Life cycle assessment

Life cycle costs

Greenhouse gas emissions

Multi-objective optimization

Genetic algorithms

\begin{abstract}
A B S T R A C T
Current practice adopted by highway agencies with regards to pavement management, has mostly consisted of employing life cycle costs analysis (LCCA) systems to evaluate the overall long-term economic efficiency of competing pavement design and maintenance and rehabilitation (M\&R) activities alternatives. This way of supporting the decision-making process as it relates to pavement management, in which little or no importance is given to environmental considerations, suggests the need for pavement management decision-support systems (DSS), which, by integrating multi-disciplinary and complementary pavement life cycle modelling approaches, enable the decision makers (DMs) to properly account for, consider and assess the lifetime impacts of their decisions and practices regarding sustainability goals and targets. This only can be achieved by employing techniques and tools provided with a comprehensive and wide-scoped cradle-to-grave capacity of analysis.

To address this multifaceted problem, this paper presents a comprehensive and modular multi-objective optimization (MOO)-based pavement management DSS which comprises three main components: (1) a MOO module; (2) a comprehensive and integrated pavement life cycle costs - life cycle assessment (LCC-LCA) module that covers the whole life cycle of the pavement; and (3) a decision-support module.

The potential of the proposed DSS is illustrated with one case study consisting of determining the optimal M\&R strategy for a one-way flexible pavement section of a typical Interstate highway in Virginia, USA, which yields the best trade-off between the following three often conflicting objectives: (1) minimization of the present value (PV) of the total life cycle highway agency costs (LCHAC); (2) minimization of the PV of the life cycle road user costs (LCRUC); and (3) minimization of the life cycle greenhouse gas emissions (LCGHG). In comparison to the traditional maintenance strategy, the proposed DSS suggest a maintenance plan that reduces LCHAC by $15 \%$, LCRUC by $28 \%$ and LCGHG by $26 \%$.
\end{abstract}

\section{Introduction}

Road infrastructure provides a fundamental foundation to the performance of all national economies, delivering a wide range of economic and social benefits. Concomitantly, it contributes significantly to the environmental footprint during its construction, maintenance and usage (Santero and Horvath, 2009). Therefore, a road network which is allowed to deteriorate will not only lead to higher road maintenance, rehabilitation and user costs over the long term, but will also lead to more pollutants emissions, traffic noise and unsafe roads, as a consequence of vehicles travelling over uneven road pavements (EUPAVE et al., 2016).

\footnotetext{
* Corresponding author.

Email addresses: joao.oliveira-dos-santos@ifsttar.fr (J. Santos); adelino@dec.uc.
} pt (A. Ferreira); flintsch@vt.edu (G. Flintsch)
A good road pavement management is therefore of crucial importance for an adequate road pavement maintenance, as it has the potential to provide decision-makers (DMs) with the required methodologies for an efficient sustainable management of road pavements (EUPAVE et al., 2016). In this context, life cycle costs analysis (LCCA) provides an effective evaluation to pinpoint cost effective solutions for the design and maintenance of pavement systems (Walls and Smith, 1998), whereas Life Cycle Assessment (LCA) can estimate the environmental impacts of a pavement system by calculating the resources and energy flows consumed and the consequent environmental effects associated with all phases of the its life cycle (Santero et al., 2011).

Despite the recognized merits of LCCA and LCA methods in evaluating the economic and environmental dimensions of sustainability, these methods applied individually are inefficient to optimally address the common trade-off of relationships and interactions between life cycle sustainability indicators. Rather, they are better em- 
ployed when integrated into an optimization-based pavement life cycle management framework accounting for various objectives and constraints, and allowing LCCA and LCA to be carried out in parallel (Keoleian and Spitzley, 2006).

However, the traditional practice in optimized decision-making in pavement management has been based on the optimization of a single objective, mostly the minimization of LCC, which can be either the total highway agency costs (HAC) or, less often, the summation of the total HAC and road user costs (RUC). It is therefore evident that a steady and effective implementation of a sustainable pavement management system (PMS), through the addition of the environmental dimension to the traditional cost-based optimization framework, requires the mathematic formulation of the decision problems to migrate from the single-objective optimization (SSO) to the multi-objective optimization (MOO) domain, in which the DMs are provided not with one single preferred solution, but with a set of potentially preferred solutions (Wu and Flintsch, 2009).

In the field of road pavement maintenance decision-making, the study performed by Zhang et al. (2010) was the first one to combine pavement maintenance and rehabilitation (M\&R) optimization and environmental assessment by assigning monetary values (marginal damage costs - MDC) to the main air pollutants. Then, the environmental MDC were combined with the HAC and RUC in a SOO model. Lidicker et al. (2013) expanded upon the optimization concepts of Zhang et al. (2010) but investigated the interrelationships of HAC and RUC and included more detailed policy analyses through a bi-objective multi-criteria optimization (MCO) model. However, only one type of pavement treatment, namely the "mill-and-fill" rehabilitation activity, was accounted for and the work zone (WZ) traffic management phase, which is one of the most environmentally damaging and costly for road users, was disregarded. Torres-Machi et al. (2017) also proposed a bi-objective MCO model for the optimal design of sustainable maintenance programs that aims to maximize the long-term effectiveness while minimizing greenhouse gas (GHG) emissions derived from the application of maintenance treatments. Bryce et al. (2014) and $\mathrm{Yu}$ et al. (2015) took a step further by moving from a bi-to a tri-objective MCO model relating costs, pavement condition and environmental impacts. However, both studies ignored the environmental burdens and the road user delay costs associated with the WZ traffic management phase. Lee et al. (2016) developed a methodology to solve a different problem, where the objectives were the minimization of HAC and RUC under a GHG emissions constraint.

Despite the undeniable merits and achievements of the above mentioned studies, all of them suffer from at least one or a combination of drawbacks such as: (1) the inability to estimate the environmental and economic burdens associated with the usage and/or WZ traffic management phases; (2) the consideration of a reduced number of M\&R treatment alternatives, which in some studies means that promising treatments for improving the sustainability of pavement systems, such as preventive and in-place recycling-based treatments, were not considered; (3) the consideration of short project analysis periods (PAPs), which do not allow for the assessment of the long-term and cumulative economic and environmental impacts resulting from the decision-making process; (4) the trade-off analysis between the costs incurred by the several pavement management stakeholders (i.e., highway agencies and road users) and environmental indicators were not carried out or if they were, they were limited to a bi-objective perspective encompassing HAC and environmental indicators, and; (5) the HAC, RUC and environmental impacts are presented in an excessively aggregated manner, making it difficult for the DMs to acquire insights into (i) the relative contribution of the subcomponents to the total figures, and (ii) the economic and environmental implications resulting from implementing new pavement management policies and practices, due to the lack of understanding of the relationship between parameters/processes and outcomes.

These limitations create the need to develop an optimization-based decision-support system (DSS) for pavement management able to identify optimal pavement M\&R strategies that properly address the potential trade-offs between environmental impacts arising from the all pavement life cycle phases and the costs incurred by the highway agencies and road users over the pavement life cycle.

Having detected this gap, this research study aims to (1) develop a comprehensive and modular MOO-based pavement management DSS for enhancing pavement sustainability and (2) illustrate its capability through a case study base on the current pavement management practices adopted by highway agencies. The main novelty of the DSS lies in the incorporation of a comprehensive and integrated pavement LCC-LCA model, that covers all pavement life cycle phases, from materials to end-of-life (EOL) phases, along with a decision-support module, within a MOO framework applicable to pavement management. The aims of the DSS are twofold: (1) to enhance the sustainability of the pavement management policies and practices by identifying the most economically and environmentally promising pavement M\&R strategies, given a set of constraints, and (2) to help DMs to select a final optimum pavement M\&R strategy among the set of Pareto optimal pavement M\&R strategies.

To achieve the main objectives of the study, this paper is organized as follows. Section 2 provides the theoretical background on the MOO and Pareto optimality concepts. Section 3 describes the main features of the proposed optimization-based DSS. This description includes the mathematical formulation of the MOO model, the approach employed to solve it, as well as the optimization algorithm. Section 4 illustrates the capabilities of the proposed DSS to determine optimal pavement M\&R strategies while providing insights on the trade-off relationships between the sustainability metrics. Finally, Section 5 concludes the paper and offers suggestions on possible opportunities for future research.

\section{Multi-objective optimization and Pareto optimality concepts}

Many real-world problems commonly require optimizing more than one objective. In general, these objectives are conflicting and compete with each other, meaning that finding a solution that is optimal for all objectives at the same time is an impossible task. Therefore, the goal becomes a search for a set of solutions that are optimal according to the Pareto optimum concept.

Without loss of generality, let us consider a MOO problem defined as (Equation (1)):

$$
\begin{aligned}
& \min F(\vec{X}) \\
&= {\left[f_{1}(\vec{X}), \ldots, f_{N_{o b j}}(\vec{X})\right]^{T} \text { subject to } \vec{X} } \\
& \quad \in \Omega
\end{aligned}
$$

where $F(\vec{X})=\left[f_{1}(\vec{X}), \ldots, f_{N_{o b j}}(\vec{X})\right]^{T}$ is the vector of objective functions, $N_{o b j}\left(N_{o b j} \geq 2\right)$ is the number of objectives, $\vec{X}=\left[x_{1}, x_{2}, \ldots, x_{n}\right]^{T}$ is the vector representing the decision variables, $\Omega ? R^{n}$ represents the set of feasible solutions associated with equality and inequality constraints and bounds, $Z=F(\Omega)$ represents the set of feasible solutions in the objective space and 
$z=F(\vec{X})=\left(y_{1}, y_{2}, \ldots, y_{N_{o b j}}\right)$, where $y_{i}=f_{i}(\vec{X})$, is a point of the objective space.

In light of the Pareto dominance concept extended to solutions, a solution $\vec{X} \in \Omega$ is called dominated by a solution $\vec{X}^{*} \in \Omega\left(\vec{X}^{*} \prec \vec{X}\right)$ if and only if (Equation (2)):

$$
\begin{aligned}
\forall i & \in\left\{1, \ldots, N_{o b j}\right\} \\
& : f_{i}\left(\vec{X}^{*}\right) \\
& \leq f_{i}(\vec{X}) \wedge \exists i \\
& \in\left\{1, \ldots, N_{o b j}\right\} \\
& : f_{i}\left(\vec{X}^{*}\right)<f_{i}(\vec{X})
\end{aligned}
$$

If strict inequality holds for all $N_{o b j}$ objective functions, then $\vec{X}^{*}$ is said to strictly dominate $\vec{X}$. The non-dominance relationship determines the concept of Pareto optimality. A solution $\vec{X}^{*} \in \Omega$ is then called Pareto optimal if for every $\vec{X} \in \Omega, \vec{X}$ does not dominate $\vec{X}^{*}$. In other words, a Pareto-optimal solution cannot be improved in one objective without losing quality in another one. The set of all these non-dominated solutions is called the Pareto optimal set and represents the solutions of the MOO problem. The objective values of the Pareto optimal set in the objective space is named Pareto front. Finding the Pareto optimal set is then the main goal when tackling a MOO problem in the Pareto sense. Given that this goal is in many circumstances computationally intractable, heuristic algorithms are commonly employed to find as good an approximation as possible to the Pareto front (Ehrgott and Gandibleux, 2004).

\section{Methods}

Taken into account the current state of the art and practice as it pertains to the incorporation of environmental considerations in pavement management systems (PMS), this section describes the main features of the proposed optimization-based DSS for enhancing pavement sustainability.

\subsection{Framework of the optimization-based decision-support system for pavement management}

The methodological framework of the DSS comprises three main modules (Fig. 1): (1) a MOO module; (2) a comprehensive and integrated pavement LCC-LCA module; and (3) a decision-support module. The MOO module is further divided into three sub-components: (i) the formulation of the MOO model, which consists of defining the decision variables, the objective functions and constraints; (ii) the solution approach, which hosts the method to be employed to solve the MOO model and find the Pareto optimal set of solutions; and (iii) the optimization algorithm developed to solve the MOO model.

In addition to the aforementioned main modules, the architecture of the DSS includes (1) a data management module, which is responsible for gathering data, storing it in several libraries and ensuring the integrity and readiness of the data required by the multiple models in- corporated into the DSS, and (2) a results report module, which provides a detailed description of the optimization results. In the following sections, each main component will be presented in detail.

\subsection{Multi-objective optimization model}

\subsubsection{Formulation}

The formulation of the MOO model was written in MATLAB ${ }^{\circledR}$ programming software (MATLAB, 2015) and encompasses three main steps: (1) identification of the decision variables of the problem to be tackled; (2) definition of the objective functions; and (3) definition of the set of constraints.

The main set of decision variables of the pavement M\&R strategy selection problem, which are defined by an integer figure, is designed to represent all feasible M\&R activities to be performed in each pavement section and in each year of the PAP. Examples of other sets of variables include those describing the pavement performance in each year of the PAP.

As far the definition of the objective functions is concerned, the main goal underlying the development of this DSS suggests the definition of objective functions representing the commonly conflicting perspectives and interests of the two main pavement management stakeholders, i.e. highway agency and road users, and also the environment. Given this, the following objectives were inserted by default into the DSS: (1) minimization of the present value (PV) of the total costs incurred by highway agencies with the construction, M\&R and EOL of a road pavement section throughout its life cycle; (2) maximization of the pavement performance over the PAP; (3) the minimization of the $\mathrm{PV}$ of the total life cycle road user costs (LCRUC) incurred during both the execution of a M\&R activity and the normal operation of the infrastructure; and (4) the minimization of the life cycle environmental burdens arising from all pavement life cycle phases. Metrics of environmental impact are obtained by employing the US-based impact assessment methodology, the Tool for the Reduction and Assessment of Chemical and other environmental Impacts 2.0 - TRACI 2.0 (Bare, 2011) from the US EPA. The TRACI impact categories available for analysis include: climate change (CC); acidification due to airborne emissions (AC), eutrophication due to airborne emissions (EU), human health criteria pollutants $(\mathrm{HH})$ and photochemical smog formation (PSF). Furthermore, three energy-based indicators are also made available: (1) primary energy obtained from fossil resources; (2) primary energy obtained from non-fossil resources; and (3) feedstock energy.

Finally, the main set of constraints to be considered in the MOO model is meant to ensure that the problem solutions comply with: (1) pavement performance quality requirements; (2) annual budget limitations; and (3) technical and policy requirements.

The MOO model introduced above with a formulation suitable for addressing the specificities of the case study described in Section 4 can be mathematically expressed as follows:

$$
\text { Minimize } \begin{array}{r}
O F_{1}=\sum_{t=1}^{P A P} \frac{1}{(1+d)^{t}} \times \sum_{r=1}^{R}\left(C_{r t}^{\text {MatExt } \operatorname{Pr} o d}\right. \\
\left.+C_{r t}^{C . M \& R}+C_{r t}^{T M}\right) \times X_{r t}
\end{array}
$$




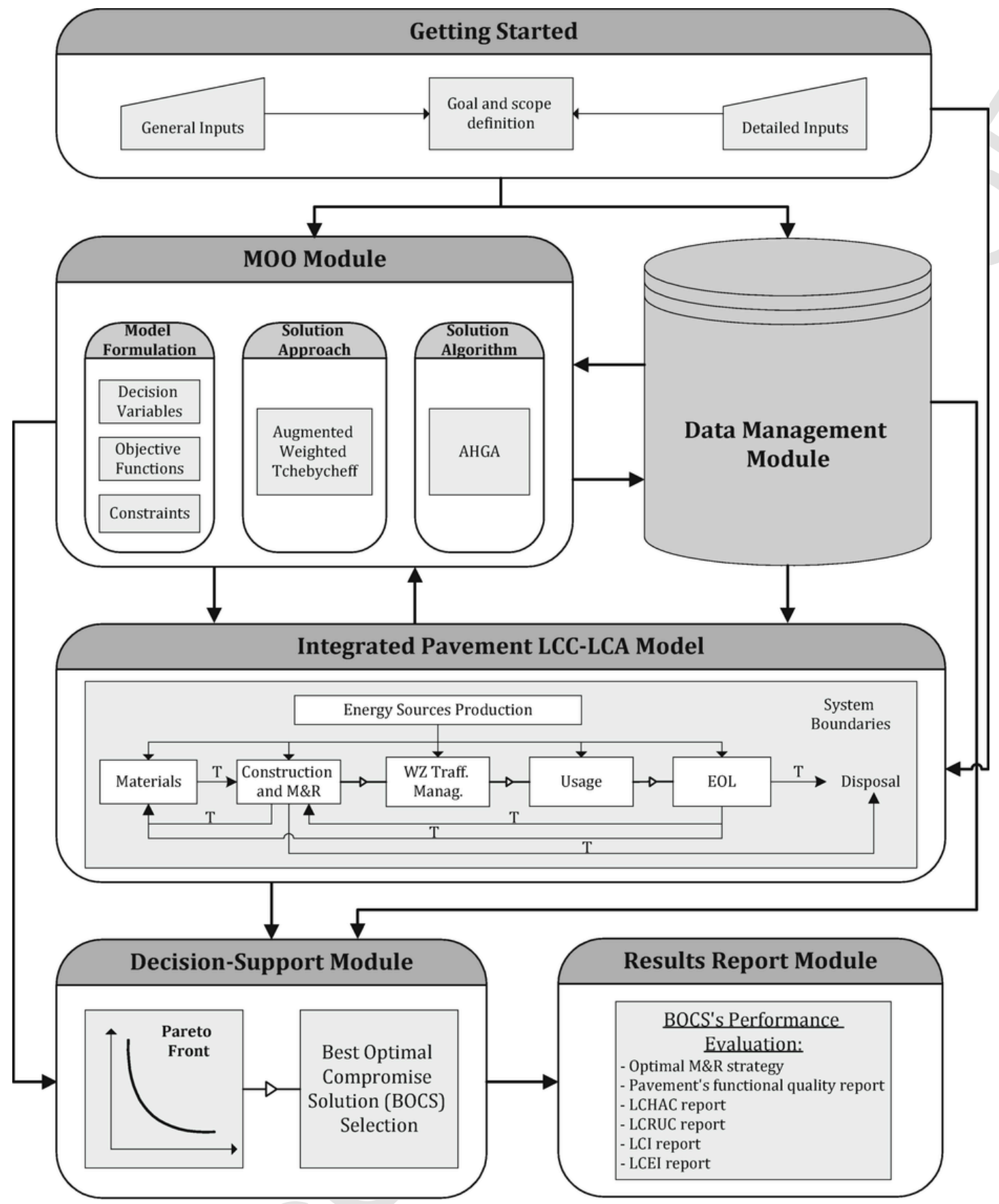

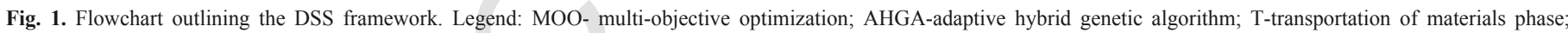

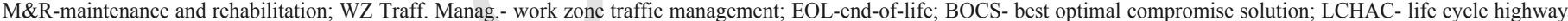
agency costs; LCRUC- life cycle road user costs; LCI- life cycle inventory; LCEI- life cycle environmental impacts. 


$$
\begin{aligned}
\text { Minimize } O F_{2}= & \sum_{t=1}^{P A P} \frac{1}{(1+d)^{t}} \\
& \times\left\{\left[\sum_{r=1}^{6}\left(V O C_{r t}^{W Z T M}+T D C_{r t}^{W Z T M}\right)\right.\right. \\
& \left.\left.\times X_{r t}\right]+V O C_{t}^{\text {Usage }}\right\}
\end{aligned}
$$

$$
\begin{aligned}
& \text { Minimize } \mathrm{OF}_{3}=\sum_{i=1}^{C_{I}} C F_{i c}^{C} \times \sum_{t=1}^{P A P}\left[\sum _ { r = 1 } ^ { R } \left(L C I_{i c r t}^{\text {MatExt } \operatorname{Pr} o d}\right.\right. \\
& +L C I_{i c r t}^{C . M \& R}+L C I_{i c r t}^{T M} \\
& \left.\left.+L C I_{i c r t}^{W Z T M}\right) \times X_{r t}+L C I_{i c t}^{U s a g e}\right]
\end{aligned}
$$

Subject to:

$$
\begin{aligned}
C C I_{t} & =\Phi\left(C C I_{0}, X_{11}, \ldots, X_{1 t}, \ldots, X_{r 1}, \ldots, X_{r t}\right), \quad r \\
& =1, \ldots, R ; \quad t \\
& =1, \ldots, P A P
\end{aligned}
$$

$$
\sum_{r=1}^{R} X_{r t}=1, \quad t=1, \ldots, \quad P A P
$$

$\Delta t_{R C} \leq \Delta t_{R C}^{\max }$

$$
\begin{aligned}
& \left\{C_{r t}^{\text {MatExt } \operatorname{Pr} o d} ; C_{r t}^{C . M \& R} ; C_{r t}^{T M}\right\} \\
& \quad=\Psi a \quad\left(C C I_{t}, X_{r t}\right), \quad r \\
& =1, \ldots, R ; \quad t \\
& \quad=1, \ldots, P A P
\end{aligned}
$$

$$
\begin{aligned}
& \begin{aligned}
\left\{V O C_{r t}^{W Z T M} ; T D C_{r t}^{W Z T M}\right\} & =\Psi u\left(C C I_{t}, X_{r t}\right), \quad r \\
& =1, \ldots, \quad R ; \quad t \\
& =1, \ldots, P A P
\end{aligned} \\
& V O C_{t}^{\text {Usage }}=\Psi u\left(C C I_{t}\right), \quad t=1, \ldots, \quad P A P
\end{aligned}
$$

$$
\begin{aligned}
& \left\{L C I_{c r t}^{M a t E x t \operatorname{Pr} o d} ; L C I_{c r t}^{C . M \& R} ; L C I_{c r t}^{T M} ; L C I_{c r t}^{W Z T M}\right\} \\
& \quad=\Psi L C I_{c} \quad\left(C C I_{t}, X_{r t}\right), \quad r \\
& \quad=1, \ldots, R ; \quad t \\
& \quad=1, \ldots, P A P ; \quad C \\
& \in I M P
\end{aligned}
$$

$$
\begin{aligned}
\left\{L C I_{i c t}^{\text {Usage }}\right\} & =\Psi L C I_{C} \quad\left(C C I_{t}\right) \\
& =1, \ldots, C_{I} ; \quad t \\
& =1, \ldots, P A P
\end{aligned}
$$

where $d$ is the discount rate; $C_{r t}^{M a t E x t \operatorname{Pr} o d}$ is the materials extraction and production phase costs incurred by the highway agency for applying M\&R activity $r$ in year $t ; C_{r t}^{C . M \& R}$ is the M\&R phase costs incurred by the highway agency for applying M\&R activity $r$ in year $t$; $C_{r t}^{T M}$ are the transportation of the materials phase costs incurred by the highway agencies for applying M\&R activity $r$ in year $t ; X_{r t}$ is equal to one if M\&R activity $r$ is applied in year $t$, otherwise it is equal to zero; $V O C_{r t}^{W Z T M}$ are the vehicle operation costs (VOC) incurred by the road users during the WZ traffic management phase due to the application of the M\&R activity $r$ in year $t$. It includes five types of VOC subcategories: (1) fuel consumption; (2) oil consumption; (3) tyre wear; (4) vehicle maintenance and repair; and (5) vehicle depreciation. $T D C_{r t}^{W Z T M}$ are the time delay costs incurred by the road users during the WZ traffic management phase due to the application of the M\&R activity $r$ in year $t ; V O C_{t}^{U s a g e}$ are the marginal VOC incurred by the road users in year $t$ of the PAP as a consequence of the deterioration of the pavement condition. It comprises four types of VOC subcategories: (1) fuel consumption; (2) tyre wear; (4) vehicle maintenance and repair; and (5) mileage-related vehicle depreciation. $C F_{i c}^{C}$ is the characterization factor for inventory flow ic contributing to the impact category $C$, which, in the total, comprises $C_{I}$ flows. $L C I_{i c r t}^{\text {MatExt } \operatorname{Pr} \text { od }}$ is the quantity of the inventory flow ic contributing to impact category $C$ released during the materials extraction and production phase associated with the execution of the M\&R activity $r$ in year $t ; L C I_{i c r t}^{C . M \& R}$ is the quantity of the inventory flow ic contributing to impact category $C$ released during the M\&R phase associated with the execution of the M\&R activity $r$ in year $t$; $L C I_{i c r t}^{T M}$ is the quantity of the inventory flow ic contributing to impact category $C$ released during the transportation of materials phase associated with the execution of the M\&R activity $r$ in year $t ; L C I_{i c r t}^{W Z T M}$ is the quantity of the inventory flow ic contributing to impact category $C$ released during the WZ traffic management phase associated with the execution of the M\&R activity $r$ in year $t ; L C I_{i c t}^{U s a g e}$ is the quantity of the inventory flow ic contributing to impact category $C$ released in year $t$ of the usage phase of the road pavement section; $C C I_{t}$ is the critical condition index (CCI) value in year $t$; $C C I_{\min }$ is the minimum CCI value allowed for a pavement structure and was set to $40 ; \Delta t_{R C}$ is the time interval between the application of two consecutives M\&R activities of type Reconstruction (RC); $\Delta t_{R C}^{\max }$ is the maximum time interval between the application of two consecutives M\&R activities of type RC; $\Phi$ are the pavement condition functions; $\Omega$ are the feasible M\&R activities sets; $\Psi a$ are the HAC functions; $\Psi u$ are the RUC functions; IMP are the set of impact categories; $\Psi L C I_{C}$ are the life cycle inventory (LCI) functions of the impact category $C$. 
Equation (3), the first objective function of this quite complex, highly non-linear discrete optimization model, expresses the minimization of the PV of the total LCHAC. Equation (4) expresses the minimization of the PV of the total LCRUC. Equation (5) expresses the minimization of total life cycle environmental burdens corresponding to a given impact category.

Constraints (6) correspond to the pavement condition functions. In this formulation they are expressed the CCI of the pavement section in each year $t$ as a set of functions of the initial condition $\left(C C I_{0}\right)$ and the M\&R activities previously applied to the pavement. Constraints (7) represent the feasible operation sets, i.e. the M\&R activities that can be applied to maintain or rehabilitate the pavement structure in relation to its quality condition. Constraints (8) are the warning level constraints which define the minimum CCI value allowed for a pavement structure. Constraints (9) indicate that only one M\&R activity should be performed in each year. Constraint (10) represents technical limitations which impose limits to the life of the initial pavement design and $\mathrm{RC}$ treatment. Its inclusion in the model is based on the VDOT criteria according to which the initial pavement design is equal to 30 years (VDOT, 2014). Constraints (11) represent the LCHAC which are computed in relation to the pavement condition and the M\&R activity applied to the pavement in a given year. Constraints (12) represent the LCRUC which are computed in relation to the M\&R activity applied to the pavement in a given year. Constraints (13) represent the LCRUC which are computed in relation to the pavement condition observed in each year $t$ of the PAP. Constraints (14) correspond to the LCI functions of the impact category $C$ which are computed in relation to the M\&R activity applied to the pavement in a given year. Constraints (15) correspond to the LCI functions of the impact category $C$ which are computed in relation to the pavement condition observed in each year $t$ of the PAP.

\subsubsection{Solution approach}

Several approaches have been developed to solve MOO problems, which include, among others, aggregation methods (e.g., weighted sum method), weighted metric methods (e.g., compromise programming methods), goal programming method, achievement functions method, goal attainment method, $\varepsilon$-constrained method, dominance-based approaches (e.g., NSGA-II, SPEA2, PESA-II, etc.) (Talbi, 2009; Marler and Arora, 2004; Miettinen, 1999). For a thorough review of the application of MOO techniques to the highway asset management problems, the reader is referred to $\mathrm{Wu}$ et al. (2012). In the proposed DSS, the augmented weighted Tchebycheff method is adopted to solve the MOO model (Därcher et al., 2012). This is a modified version of the compromise programming method in which the value of the parameter $p$ is equal to $\infty$. Unlike the widely applied weighted sum method, it can be applied to generate solutions on the non-convex portions of the Pareto front and overcomes the drawback of its unmodified version by alleviating the potential for solutions that are only weakly Pareto optimal (Marler and Arora, 2004). In order for this method to be applied to MOO problems, they are converted into a SOO one, by combining the several objectives into a single objective. Its formulation is illustrated as follow (Equations (16) and (17)):

$$
\max _{i=1, \ldots, 3}\left[w_{i} \times \frac{f_{i}(\vec{X})-f_{i}^{\min }}{f_{i}^{\max }-f_{i}^{\min }}\right]+\rho \times \sum_{i=1}^{N_{\text {obj }}} \frac{f_{i}(\vec{X})-f_{i}^{\min }}{f_{i}^{\max }-f_{i}^{\min }}
$$

Subject to:

$$
\begin{aligned}
& w_{i} \geq 0, \quad i=1, \ldots, N_{o b j}, \quad \sum_{i=1}^{N o b j} w_{i}=1, \quad \rho \in \mathfrak{R} \\
& w_{i}+\rho>0, \quad i=1, \ldots, N_{o b j}
\end{aligned}
$$

where $w_{i}$ is the weight assigned to the objective $i$, which varies from 0 to 1 in an increment step of $0.01 ; f_{i}(\vec{X})$ is the value of the objective function $i$ for the solution $\vec{X} ; f_{i}^{\min }$ is the minimum allowed value of the $i$ th objective function; $f_{i}^{\max }$ is the maximum allowed value of the $i$ th objective function; $N_{o b j}$ is the number of objectives for the MOO problem being considered and $\rho$ is a non-negative scalar, which was set at $10^{-3}$ based on Steuer (1986).

\subsubsection{Solution algorithm}

The optimization model described in the previous sections is extremely difficult to solve to an exact optimum given its marked combinatorial nature and the difficulties in verifying, when they exist, the required mathematical properties of continuity, convexity and derivability. In fact, previous experience with a segment-linked optimization model (Ferreira et al., 2002), has shown that we cannot rely on exact methods to find guaranteed optimal solutions within an acceptable time period when applying this type of models to a real-world road network. Even for small-size instances, those algorithms may require impractically high computational times to solve them to the exact optimum when the pavement performance in the years following the application of a given treatment is modelled through a non-linear equation, which varies depending on the type of the last treatment, and in some circumstances, on the type of treatments preceding the last one, as in the case study introduced later in this paper. Therefore, to solve the transformed SOO model, and thus generate the Pareto front, the genetic algorithm (GA)-based search heuristic developed by Santos et al. (2017a) was employed. Although the GA has been presented in the aforementioned references, a brief overview of the method is provided in this section because it is a core component of the optimization-based DSS introduced in this paper.

This GA possesses a hybrid nature in that Local Search (LS) techniques have been incorporated into the traditional GA framework to improve the overall efficiency of the search. Specifically, it contains two dynamic learning mechanisms to adaptively guide and combine the exploration and exploitation search processes. The first learning mechanism aims to reactively assess the worthiness of conducting an LS and to efficiently control the computational resources allocated to the application of this search technique. The second learning mechanism uses instantaneously learned probabilities to select which one, from a set of pre-defined LS operators which compete against each other for selection, is the most appropriate for a particular stage of the search to take over from the evolutionary-based search process.

Compared to its initial version, a change was made in the set of LS operators available for on-line selection. In particular, the "delete" LS operator originally defined by Santos et al. (2017a) was replaced by another one, named "displacement" LS operator, which can be described by the following steps: (1) randomly select a subchromosome corresponding to the time period between the application of two of the most structurally robust M\&R activities; (2) randomly select one gene of the subchromosome which encodes a real M\&R activity; (3) displace backwards all genes between the first gene of the subchromosome and the gene picked in the previous step; (4) in the position of the gene picked in step (1) encode a "Do Nothing" (DN) M\&R ac- 
tivity. The remainders components and parameters of the algorithm remained unchanged.

\subsection{Integrated pavement life cycle costs - life cycle assessment model}

The integrated pavement LCC-LCA model follows a cradle-to-grave approach, and consists of a parallel application of the LCA methodology taking into account, as far as possible and suitable, the guidelines provided by the International Standard Organization (ISO) (ISO, 2006a; ISO, 2006b) and the University of California Pavement Research Center (UCPRC) Pavement LCA Guideline (Harvey et al., 2010) and the LCC methodology based on Swarr et al. (2011).

The pavement life cycle model covers six phases: (1) materials extraction and production; (2) construction and M\&R; (3) transportation of materials; (4) WZ traffic management; (5) usage; and (6) EOL. These phases were broken down into multiple components which connect to each other by data flows computed through a hybrid LCI approach. Specifically, the monetary flows associated with exchanges of the pavement life cycle system that are directly covered by the LCC model but for which specific process data are either completely or partially unavailable are combined with an Input-Output (I-O) methodology for deriving the underpinning environmental burdens. By interactively integrating the strengths of process-based LCI (P-LCI) and I-O LCI, the resources which are readily available are used in a more efficient, consistent and rational way and with less effort, helping to reduce the "cutoff" errors and improving the consistency between the system boundaries of the pavement life cycle when analysed concomitantly from the economic and environmental viewpoint.

For this purpose, the pavement LCC-LCA model builds on the process-based LCA (P-LCA) and LCC models introduced by Santos et al. (2015a, 2015b, 2015c), respectively, and complement them with the Carnegie Mellon University's Economic Input-Output Life Cycle Assessment tool (EIO-LCA) (Carnegie Mellon University Green Design Institute, 2010). This tool utilizes the Leontief's methodology to relate the inter-sector monetary transactions sectors in the US economy, compiled in a set of matrices by the Bureau of Economic Analysis (BEA) of the US Department of Commerce, with a set of environmental indicators (e.g., consumption of fossil energy, airborne emissions, etc.) per monetary output of each industry sector of the economy. The environmental burdens at sector level associated with a particular commodity under analysis are therefore calculated by multiplying its monetary value, previously adjusted to US dollars of the EIO-LCA model's year according to sector-specific economic indices from the US Department of Labor, by the respective sectorial environmental multipliers obtained from the EIO-LCA model.

\subsection{Decision-support model}

Once a set of non-dominated solutions is generated representing the optimums for the problem being tackled, the DM faces a MCDM problem should he desire to choose a single Pareto optimal solution out of the Pareto optimal set. A natural idea would be to choose the solution in the Pareto front furthest from the most inferior solution, in which the most inferior solution is the one with the maximum value for all objectives, assuming that all the objective functions are meant to be minimized. In order to assist the DM with this task, a decision-support model is implemented in the proposed DSS, where the calculation of distances from the most inferior solution relies on the membership function concept in the fuzzy set theory (Zimmormann, 1996).
According to the adopted methodology the accomplishment level of each non-dominated solution $j$ in satisfying the objective $i$ is given by the membership function represented by Equation (18). The sum of the accomplishment levels of each non-dominated solution $j$ is posteriorly rated with respect to all the $M$ non-dominated solutions by normalizing its accomplishment over the sum of the accomplishments of the $M$ non-dominated solutions (Equation (19)). The normalized membership function $\beta_{j}$ provides de fuzzy cardinal priority ranking of each non-dominated solution $j$. The solution with the maximum value of $\beta_{j}$ is considered as the best optimal compromise solution (BOCS).

$$
\begin{aligned}
& u_{i}^{j}=\frac{f_{i}^{\max }-f_{i}^{j}}{f_{i}^{\max }-f_{i}^{\min }} \\
& \beta_{j}=\frac{\sum_{i=1}^{N_{o b j} j} u_{i}^{j}}{\sum_{i=1}^{N_{o b j}} \sum_{j=1}^{M} u_{i}^{j}}
\end{aligned}
$$

where $u_{i}^{j}$ is the membership function value for the $j$ th non-dominated solution with respect to the $i$ th objective; $f_{i}^{\max }$ and $f_{i}^{\min }$ are the maximum and minimum values of the $i$ th objective, respectively; $j_{i}$ is $i$ th objective value for the $j$ th non-dominated solution; $\beta_{j}$ is the normalized membership function value for the $j$ th non-dominated solution; $N_{o b j}$ is the number of objectives for the MOO problem; and $M$ is the number of non-dominated solutions.

\section{Case study \\ 4.1. General description}

In order to illustrate the capabilities of the proposed DSS, it is applied to a case study consisting of determining the optimal M\&R strategy for a one-way flexible pavement section of a typical Interstate highway in Virginia, USA, that yields the best trade-off between the following three often conflicting objectives: (1) minimization of the PV of the total LCHAC; (2) minimization of the PV of the LCRUC; and (3) minimization of the life cycle environmental impacts (LCEI), namely the Climate Change (CC) score. CC was selected because it is increasingly regulated and discussed by both governmental and non-governmental institutions. The characterization factors for the gases carbon dioxide $\left(\mathrm{CO}_{2}\right)$, methane $\left(\mathrm{CH}_{4}\right)$ and nitrous oxide $\left(\mathrm{N}_{2} \mathrm{O}\right)$ given by the International Panel on Climate Change's (IPCC's) characterization model for a horizon period of 100 years (IPCC, 2007) were considered.

Furthermore, two scenarios were considered depending on whether or not the most structurally robust M\&R activity available for employment throughout the PAP includes recycling-based layers. The features of the case study is shown in Table 1.

The road pavement section previously described was assessed according to its economic and environmental performances in the following pavement life cycle phases: (1) materials extraction and production; (2) construction and M\&R; (3) transportation of materials; (4) WZ traffic management; and (5) usage. The EOL phase was excluded from the system boundaries because the road pavement section is expected to remain in place after reaching the end of the PAP, serving as a support for the new pavement structure. In view of this scenario, the salvage values of the pavement structure is given as the value of its remaining service life, which was proven to be negligible 
Table 1

Features of the case study.

\begin{tabular}{lll}
\hline Name & \multicolumn{2}{l}{ Parameter } \\
\hline & value & unit \\
\hline PAP & 50 & year \\
Beginning year & 2011 & year \\
Initial annual average daily traffic (AADT $)$ & 20000 & vehicle \\
Percentage of passenger cars (PCs) in the AADT & 75 & $\%$ \\
Percentage of heavy vehicles (HDVs) in the AADT & 25 & $\%$ \\
Traffic growth rate & 3 & $\% /$ year \\
Initial CCI & 87 & - \\
Initial IRI & 1.27 & $\mathrm{~m} / \mathrm{km}$ \\
Age & 5 & year \\
Number of lanes & 2 & - \\
Lanes length & 1 & $\mathrm{~km}$ \\
Lanes width & 3.66 & $\mathrm{~m}$
\end{tabular}

Legend: PAP- project analysis period; AADT-annual average daily traffic; PCpassenger car; HDV- heavy duty vehicle; CCI- critical condition index; IRIinternational roughness index.

when compared to the costs incurred during the remaining pavement life cycle phases (Santos et al., 2015c). With regard to the environmental impacts assigned to this phase, they were disregarded on the basis of the 'cut-off' allocation method, which is the most-widely used technique to handle the EOL phase in pavements LCAs (Aurangzeb et al., 2014). According to this technique, all benefits are given to the pavement taking advantage of the reduction in the use of virgin materials due to the structural capacity provided by the existing pavement structure.

For detailed information on the processes within the system boundaries of each life cycle phase, applied modelling methodologies, assumptions and relevant data sources, the reader is referred to Santos et al. (2017b).

\subsection{Maintenance and rehabilitation activities}

The M\&R activities considered for application over the PAP were based on Chowdhury (2011), and defined as Do Nothing (DN), Preventive Maintenance (PrM), Corrective Maintenance (CM), Restorative Maintenance (RM) and RC. In the case of the PrM treatments, two types of treatments were considered: microsurfacing and thin hot mix asphalt overlay concrete (THMACO). As for the RC treatment, two alternatives were also considered. They were named conventional RC and recycling-based $\mathrm{RC}$ and differ from each other in that the former comprises exclusively conventional asphalt layers, whereas the latter consists of a combination of conventional asphalt layers with in-place recycling layers. The recycling-based RC activity was designed in such a way that it provides equivalent structural capacity to its non-recycling-based counterpart and takes into account the VDOT's surface layers requirements for layers placed over recycling-based layers (VDOT, 2013). Details on the M\&R actions comprising each M\&R activity are shown in Table 2 . The total unitary costs of each M\&R activity are presented in Table 3 and were computed according to the methodology presented in Santos et al. (2015c). The value of the unit costs of travel time required to calculate the time delay costs incurred by the road users during the WZ traffic management phase due to the application of the M\&R activities are given in Table 4. The PV of all future costs were determined by using a discount rate equal to $2.3 \%$ (OMB, 2013). The methodologies and formulations adopted to calculate the multiple subcategories of HAC and RUC, as well as the LCI associated with the several pavement life cycle phases, are presented in Santos et al. (2015b, 2015c, 2017b).
Table 2

Types of M\&R activities and M\&R actions

\begin{tabular}{|c|c|c|c|c|}
\hline $\begin{array}{l}\text { M\&R } \\
\text { activity } \\
\text { ID }\end{array}$ & $\begin{array}{l}\text { M\&R activity } \\
\text { name }\end{array}$ & M\&R actions & $\begin{array}{l}\text { Thickness } \\
(\mathrm{cm})\end{array}$ & Mixture name \\
\hline 1 & $\mathrm{DN}$ & - & - & \\
\hline \multirow[t]{3}{*}{2} & Microsurfacing & $\begin{array}{l}\text { Surface preparation: } \\
\text { brushing }\end{array}$ & - & \\
\hline & & $\begin{array}{l}\text { Surface preparation: } \\
\text { tack coat application }\end{array}$ & - & $\begin{array}{l}\text { Diluted } \\
\text { bituminous }\end{array}$ \\
\hline & & $\begin{array}{l}\text { Microsurfacing } \\
\text { spreading }\end{array}$ & & $\begin{array}{l}\text { Microsurf.- } \\
\text { Type } C^{\mathrm{a}}\end{array}$ \\
\hline \multirow[t]{4}{*}{3} & THMACO & Mill surface layer & $1.91(0.75$ & - \\
\hline & & $\begin{array}{l}\text { Surface preparation: } \\
\text { brushing }\end{array}$ & - & - \\
\hline & & $\begin{array}{l}\text { Surface preparation: } \\
\text { tack coat application }\end{array}$ & - & $\begin{array}{l}\text { Bituminous } \\
\text { emulsion }\end{array}$ \\
\hline & & $\begin{array}{l}\text { Thin overlay placement } \\
\text { and compaction }\end{array}$ & $\begin{array}{l}1.91(0.75 \\
\text { in.) }\end{array}$ & THMACO $^{\mathrm{b}}$ \\
\hline \multirow[t]{7}{*}{4} & $\mathrm{CM}$ & Mill surface layer & 5.08 ( 2 in. $)$ & - \\
\hline & & $\begin{array}{l}\text { Mill full-depth prior } \\
\text { patching } 1 \%\end{array}$ & $\begin{array}{l}25.4(10 \\
\text { in. })\end{array}$ & - \\
\hline & & Surface cleaning & - & - \\
\hline & & $\begin{array}{l}\text { Prime coat application } \\
\text { prior full-depth } \\
\text { patching }\end{array}$ & - & $\begin{array}{l}\text { Bituminous } \\
\text { emulsion }\end{array}$ \\
\hline & & $\begin{array}{l}\text { Pre-overlay full-depth } \\
\text { patching } 1 \%\end{array}$ & $\begin{array}{l}25.4(10 \\
\text { in. })\end{array}$ & BM $25.0^{\mathrm{c}}$ \\
\hline & & Tack coat application & - & $\begin{array}{l}\text { Bituminous } \\
\text { emulsion }\end{array}$ \\
\hline & & $\begin{array}{l}\text { Lay down and } \\
\text { compaction of AC } \\
\text { surface layer }\end{array}$ & 5.08 ( 2 in.) & $\operatorname{SM} 12.5^{\mathrm{c}}$ \\
\hline \multirow[t]{9}{*}{5} & RM & $\begin{array}{l}\text { Mill surface and } \\
\text { intermediate layers }\end{array}$ & $\begin{array}{l}8.89(3.5 \\
\text { in.) }\end{array}$ & - \\
\hline & & $\begin{array}{l}\text { Mill full-depth prior } \\
\text { patching } 1 \%\end{array}$ & $\begin{array}{l}21.59(8.5 \\
\text { in.) }\end{array}$ & - \\
\hline & & Surface cleaning & - & - \\
\hline & & $\begin{array}{l}\text { Prime coat application } \\
\text { prior full-depth } \\
\text { patching }\end{array}$ & - & $\begin{array}{l}\text { Bituminous } \\
\text { emulsion }\end{array}$ \\
\hline & & $\begin{array}{l}\text { Pre-overlay full-depth } \\
\text { patching } 1 \%\end{array}$ & $\begin{array}{l}21.59(8.5 \\
\text { in.) }\end{array}$ & BM $25.0^{\mathrm{c}}$ \\
\hline & & Tack coat application & - & $\begin{array}{l}\text { Bituminous } \\
\text { emulsion }\end{array}$ \\
\hline & & $\begin{array}{l}\text { Lay down and } \\
\text { compaction of the AC } \\
\text { intermediate layer }\end{array}$ & 5.08 ( 2 in. $)$ & IM $19.0^{c}$ \\
\hline & & Tack coat application & - & $\begin{array}{l}\text { Bituminous } \\
\text { emulsion }\end{array}$ \\
\hline & & $\begin{array}{l}\text { Lay down and } \\
\text { compaction of the AC } \\
\text { surface layer }\end{array}$ & $\begin{array}{l}3.81(1.5 \\
\text { in.) }\end{array}$ & $\mathrm{SM} 12.5^{\mathrm{c}}$ \\
\hline \multirow[t]{7}{*}{6} & $\begin{array}{l}\text { Conventional } \\
\mathrm{RC}\end{array}$ & $\begin{array}{l}\text { Mill surface, } \\
\text { intermediate, base } \\
\text { layers and } 1 \mathrm{in.} \\
\text { unbound layer }\end{array}$ & $\begin{array}{l}33.02(13 \\
\text { in.) }\end{array}$ & - \\
\hline & & Subgrade compaction & - & - \\
\hline & & Prime coat application & - & $\begin{array}{l}\text { Bituminous } \\
\text { emulsion }\end{array}$ \\
\hline & & $\begin{array}{l}\text { Lay down and } \\
\text { compaction of the AC } \\
\text { base layer }\end{array}$ & $\begin{array}{l}17.78(7 \\
\text { in. })\end{array}$ & BM $25.0^{\mathrm{c}}$ \\
\hline & & Tack coat application & - & $\begin{array}{l}\text { Bituminous } \\
\text { emulsion }\end{array}$ \\
\hline & & $\begin{array}{l}\text { Lay down and } \\
\text { compaction of the AC } \\
\text { intermediate layer }\end{array}$ & $\begin{array}{l}10.16(4 \\
\text { in. })\end{array}$ & IM $19.0^{c}$ \\
\hline & & Tack coat application & - & $\begin{array}{l}\text { Bituminous } \\
\text { emulsion }\end{array}$ \\
\hline
\end{tabular}


Table 2 (Continued)

\begin{tabular}{|c|c|c|c|c|}
\hline $\begin{array}{l}\text { M\&R } \\
\text { activity } \\
\text { ID }\end{array}$ & $\begin{array}{l}\text { M\&R activity } \\
\text { name }\end{array}$ & M\&R actions & $\begin{array}{l}\text { Thickness } \\
(\mathrm{cm})\end{array}$ & Mixture name \\
\hline \multirow{8}{*}{7} & \multirow{8}{*}{$\begin{array}{l}\text { Recycling- } \\
\text { based RC }\end{array}$} & $\begin{array}{l}\text { Lay down and } \\
\text { compaction of the AC } \\
\text { surface layer }\end{array}$ & 5.08 (2 in.) & $\mathrm{SM} 12.5^{\mathrm{c}}$ \\
\hline & & $\begin{array}{l}\text { Mill surface, } \\
\text { intermediate, base } \\
\text { layers and } 1 \text { in. } \\
\text { unbound layer }\end{array}$ & $\begin{array}{l}33.02(13 \\
\text { in.) }\end{array}$ & - \\
\hline & & Subgrade compaction & - & - \\
\hline & & $\begin{array}{l}\text { Lay down and } \\
\text { compaction of CCPR } \\
\text { materials in base } \\
\text { course }\end{array}$ & $\begin{array}{l}20.32(8 \\
\text { in.) }\end{array}$ & $\begin{array}{l}\text { CCPR } \\
\text { materials }^{\mathrm{d}, \mathrm{e}}\end{array}$ \\
\hline & & Tack coat application & - & $\begin{array}{l}\text { Bituminous } \\
\text { emulsion }\end{array}$ \\
\hline & & $\begin{array}{l}\text { Lay down and } \\
\text { compaction of the AC } \\
\text { intermediate layer }\end{array}$ & 7.62 (3 in.) & IM $19.0^{\mathrm{c}}$ \\
\hline & & Tack coat application & - & $\begin{array}{l}\text { Bituminous } \\
\text { emulsion }\end{array}$ \\
\hline & & $\begin{array}{l}\text { Lay down and } \\
\text { compaction of the AC } \\
\text { surface layer }\end{array}$ & 5.08 ( 2 in.) & SM $12.5^{\mathrm{c}}$ \\
\hline
\end{tabular}

Legend: BM-base material; IM-intermediate material; SM-surface material; ACasphalt concrete; CCPR-cold central plant recycling; THMACO- thin hot mix asphalt concrete overlay; $\mathrm{DN}$ - do nothing; CM-corrective maintenance; RM-restorative maintenance; RC- reconstruction.

Notes:

${ }^{a}$ Based on Ducasse et al. (2004), a mix formulation consisting of $180 \mathrm{~L}$ of emulsion per $\mathrm{m}^{3}$ aggregates, $3 \%$ of SBR by weight of asphalt binder, $2 \%$ of Portland cement by weight of aggregate and $140 \mathrm{~L}$ of water by $\mathrm{m}^{3}$ of aggregate was used.

${ }^{b}$ Mix formulation consists of $58.9 \%$ coarse aggregates, $36.1 \%$ fine aggregates, $5 \%$ asphalt binder PG 70-28 and 1\% hydrated lime by weight of asphalt binder (VDOT, 2012).

c All mixes have a reclaimed asphalt pavement (RAP) content equal to $15 \%$. For details on mixes properties the reader is referred to Santos et al. (2017b).

d A layer coefficient value of 0.40 was used for design purpose based on Diefenderfer and Apeagyei (2014).

e A PG 64-22 asphalt binder at a content of $2 \%$ by weight of total mixture was used to produce the foamed asphalt mix. For each mix, $1 \%$ of hydraulic cement and $1 \%$ of moisture were added and mixed before the foamed asphalt was added (Diefenderfer and Apeagyei, 2014).

Table 3

Unit costs of the M\&R activities.

\begin{tabular}{lll}
\hline ID & Name & Total MC (\$/Km.lane) \\
\hline 1 & DN & 0 \\
2 & PrM: microsurfacing & 6621 \\
3 & PrM: THMACO & 17,593 \\
4 & CM & 35,696 \\
5 & RM & 58,969 \\
6 & Conventional RC & 199,594 \\
7 & RC & 120,960 \\
\hline
\end{tabular}

Legend: MC- maintenance and rehabilitation costs; DN- do nothing; PrM-preventive maintenance; THMACO- thin hot-mix asphalt concrete overlay; CM-corrective maintenance; RM-restorative maintenance; RC-reconstruction/rehabilitation.

In order to provide insights into the economic and environmental advantages resulting from applying recycling-based M\&R activities as opposed to conventional ones, M\&R activities 6 and 7 were considered mutually exclusive. Therefore, in the first analysis scenario the set of feasible $M \& R$ activities comprises $M \& R$ activities numbers 1 , $2,3,4,5$ and 6 , whereas in the second analysis scenario M\&R ac-
Table 4

Unit cost of travel time for the several categories of vehicles.

\begin{tabular}{ll}
\hline Item & Unit cost of travel time (\$/hr) \\
\hline Hourly time value of passenger cars (PCs) & 28.70 \\
Hourly time value of single-unit trucks (SUTs) & 22.42 \\
Hourly time value of combination-unit trucks & 29.27 \\
(CUTs) & \\
Hourly freight inventory costs for SUTs & 0.21 \\
Hourly freight inventory costs for CUTs & 0.31
\end{tabular}

Legend: PC- passenger car; SUT-single-unit truck; CUT-combination unit truck.

tivity number 6 is replaced by its recycling-based counterpart (i.e. M\&R activity number 7).

\subsection{Pavement performance modelling}

In order to determine the pavement performance over time, the Virginia Department of Transportation's (VDOT's) pavement performance prediction models (PPPM) were used. VDOT developed a set of PPPM in units of CCI as a function of time and category of the last M\&R activity applied. CCI stands for Critical Condition Index and is an aggregated indicator ranging from 0 (complete failure) to 100 (perfect pavement) that represents the worst of either load-related or non-load-related distresses.

Using the base form corresponding to Equation (5), VDOT defines PPPM for the following types of M\&R activities (Stantec Consulting Services and Lochner, 2007): CM, RM and CM. The coefficients of VDOT's load-related PPPM represented by Equation (20) for asphalt pavements of Interstate highways are presented in Table 5.

$$
C C I(t)=C C I_{0}-e^{a+b \times c} \ln \left(\frac{1}{t}\right)
$$

where $C C I(t)$ is the critical condition index in year $t$ since the last $\mathrm{M} \& \mathrm{R}$ activity, i.e. CM, RM or RC; $C C I_{0}$ is the critical condition index immediately after treatment; and $a, b$, and $c$ are the load-related PPPM coefficients (Table 5).

Unlike the previous M\&R activity categories, VDOT did not develop individual PPPM for PrM treatments. Thus, in this case study the considered PrM treatments, i.e. microsurfacing and THMACO, were respectively modelled as an 8-point and 15-point improvement in the CCI of the road segment. Once the treatment is applied, it is assumed that the pavement deteriorates according to the PPPM of a $\mathrm{CM}$, but without reduction of the effective age. On the other hand, in the case of the application of CM, RM and RC treatments, the CCI is brought to the condition of a brand new pavement (CCI equal to 100) and the age is restored to 0 regardless of the CCI value prior to the M\&R activity application.

For the purpose of estimating the environmental impacts and costs incurred by road users during the pavement usage phase due to the vehicles travelling over a rough pavement surface, a linear roughness prediction model, expressed in terms of International Roughness In-

Table 5

Coefficients of VDOT's load-related PPPM expressed by Equation (5) for asphalt pavements of interstate highways.

\begin{tabular}{lllll}
\hline M\&R activity category & $C C I_{0}$ & $a$ & $b$ & $c$ \\
\hline CM & 100 & 9.176 & 9.18 & 1.27295 \\
RM & 100 & 9.176 & 9.18 & 1.25062 \\
RC & 100 & 9.176 & 9.18 & 1.22777 \\
\hline
\end{tabular}


dex (IRI), was considered (Equation (21)).

$$
I R I(t)=I R I_{0}+I R I_{g r w} \times t,
$$

where $I R I(t)$ is the IRI value $(\mathrm{m} / \mathrm{km})$ in year $t$; IRI $I_{0}$ is the IRI immediately after the application of a given M\&R activity; and $I R I_{g r w}$ is the IRI growth rate over time, which was set at $0.08 \mathrm{~m} / \mathrm{km}$ (Bryce et al., 2014). It was assumed that the application of an M\&R activity other than PrM restore the IRI to the value of a brand new pavement (IRI equal to $0.87 \mathrm{~km} / \mathrm{h}$ ). The IRI reduction due to the application of a PrM treatment was determined based on the expected treatment life and assuming that there is no change in the value after the PrM application (the same assumption was also made in the case of the remaining M\&R activities). Thus, by assuming treatment life periods of 3 and 5 years (Chowdhury, 2011), respectively for microsurfacing and THMACO treatments, reductions in the IRI value of 0.24 and $0.40 \mathrm{~m} /$ $\mathrm{km}$ were obtained.

\subsection{Results and discussion}

This subsection presents the results of the application of the DSS to the two maintenance scenarios for the case study previously described. They were obtained after running the DSS on a computational platform Intel Core 2 Duo $2.4 \mathrm{GHz}$ processor with $4.00 \mathrm{~GB}$ of RAM, on the Windows 7 professional operating system.

\subsubsection{Non-recycling-based maintenance and rehabilitation strategies}

Fig. 2 displays the Pareto optimal set of solutions in the objective space, outlining the optimal pavement $M \& R$ strategies for the non-recycling-base case study, along with the M\&R strategy defined by VDOT. Complementarily, to determine the strength of the relationship between the objectives considered in the MOO analysis, and thus help to interpret the behavior of the Pareto front, a Spearman's correlation analysis was performed. It uses a correlation coefficient, named Spearman rank correlation coefficient $\left(r_{s}\right)$ to measure the monotonic relationship between two variables (i.e., whether one variable tends to take either a larger or smaller value, though not necessarily

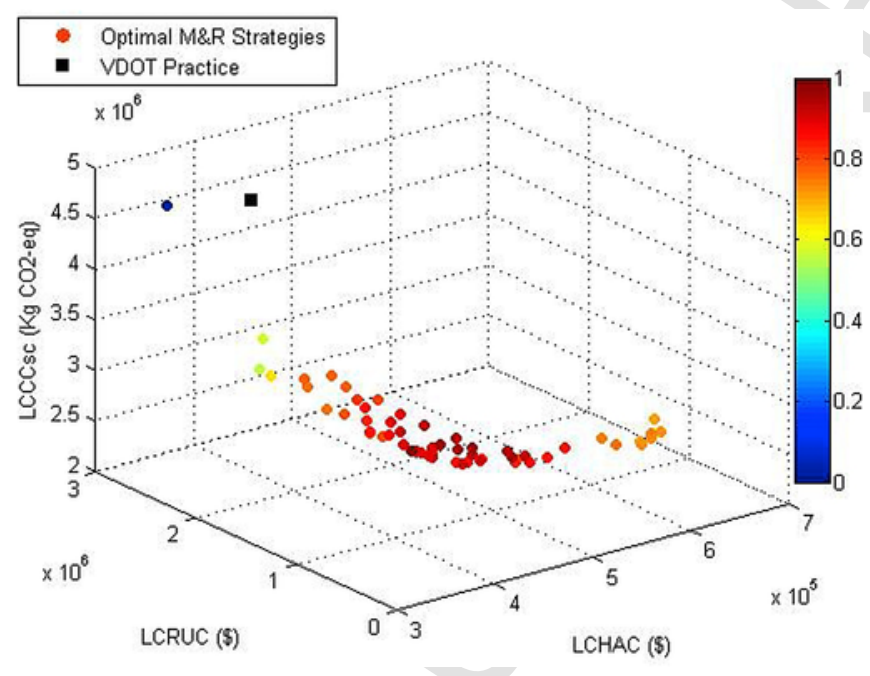

Fig. 2. M\&R strategy defined by VDOT and non-recycling-based Pareto optimal fronts. Legend: LCHAC- life cycle highway agency costs; LCRUC- life cycle road user costs; LCCCsc-life cycle climate change score. Note: The fuzzy cardinal priority ranking of each non-dominated solution was normalized so that it falls into the range $[0 ; 1]$. linearly) by increasing the value of the other variable (Equation (22)) (Machin et al., 2007). The value of the correlation coefficient defines two properties of the correlation: (1) the sign of $r_{s}$ (i.e., negative or positive) defines the direction of the relationship and (2) the absolute value of $r_{s}$, which varies between -1 and 1 , indicates the strength of the correlation. In turn, the square of $r_{s}$, called the coefficient of determination, gives the proportion of the variation of one variable explained by the other (Zou et al., 2003).

The Spearman rank correlation method was employed in detriment of the well-known Pearson correlation method because the former does not require the assumptions of normality and linearity. Furthermore, to test whether a calculated $r_{s}$ value is significantly different from a hypothesized population correlation coefficient $(\rho)$ of zero, a significant test was used. The statistical test of the null hypothesis $\rho=0$ is given by Equation (23) and follows a Students' $t$-distribution with $d f=n-2$ (Machin et al., 2007).

$$
r_{s}=1-\frac{6 \times \sum_{i=1}^{n} d_{i}^{2}}{n^{3}-n}
$$

$$
t=r_{s} \times \frac{\sqrt{n-2}}{\sqrt{1-r_{s}^{2}}}
$$

where $r_{s}$ is the Spearman rank correlation coefficient; $d_{i}$ is the difference in paired ranks $i ; n$ is the number of paired ranks; and $t$ is the two tailed $t$-test value calculated for a significance level $(\alpha)$ of 0.05 . The $r_{s}$ and $r_{s}^{2}$ values along with the statistical tests results are presented in Table 6 .

The results presented in Table 6 show a 'very strong' correlation between the LCHAC and LCCCsc, while the correlations between LCHAC and LCRUC and between LCRUC and LCCCsc are only 'strong'. In other words, an increase in the LCHAC not only leads to a reduction in the LCRUC but it is also beneficial in reducing the LCCCsc.

As far the statistical significance of the relationships between the objective functions described above is concerned, the results presented in Table 6 provide evidence in support of the rejection of the null hypothesis $(\mid t($ calc $) \mid>t(0.05))$ in all statistical hypothesis tests undertaken.

Table 6

Spearman rank correlation coefficient values, determination coefficient values and statistical tests results $\left(r_{s} ; r_{s}^{2} ; t(\right.$ calc. $\left.) ; t(\alpha=0.05)\right)$.

\begin{tabular}{llll}
\hline & LCHAC & LCRUC & LCCCsc \\
\hline LCHAC & - & $-0.70 ; 0.49 ;-8.575 ;$ & $-0.81 ; 0.65 ;-21.229 ;$ \\
& & 2.001 & 2.001 \\
LCRUC & $-0.70 ; 0.49 ;-8.575 ;$ & - & $0.74 ; 0.55 ; 4.931 ;$ \\
& 2.001 & & 2.001 \\
LCCCsc & $-0.81 ; 0.65 ;-21.229 ;$ & $0.74 ; 0.55 ; 4.931 ;$ & - \\
& 2.001 & 2.001 & \\
\hline
\end{tabular}

Legend: LCHAC- life cycle highway agency costs; LCRUC- life cycle road user costs; LCCCsc-life cycle climate change score; rs- Spearman rank correlation coefficient; rs2-coefficient of determination; $\mathrm{t}$ (calc.)- two tailed $t$-test value calculated for a significance level $(\alpha)$ of $0.05 ; \mathrm{t}(\alpha=0.05)$ - critical value of the $\mathrm{t}$-distribution for $\alpha$ equal to 0.05 .

Key (http://www.statstutor.ac.uk/): $r_{s}=0$ : no correlation; $\left.r_{s} \in\right] 0 ; 0.2[$ : very weak correlation; $r_{s} \in\left[0.2 ; 0.4\left[\right.\right.$ : weak correlation; $r_{s} \in\left[0.4 ; 0.6\left[\right.\right.$ : moderate correlation; $r_{s}$ $\in\left[0.6 ; 0.8\left[\right.\right.$ : strong correlation; $r_{s} \in\left[0.8 ; 1\left[\right.\right.$ : very strong correlation; $r_{s}=1$ : perfect correlation. 
From the analysis of Fig. 2 one can see that the shape of the Pareto front is better described as a cloud of points, meaning that highway agencies are presented with a greater variety of potential solutions within a narrow range of LCHAC values. Furthermore, a careful analysis of this Figure reveals that there is an investment level after which the Pareto front denote a flat trend. That trend means that any increase in pavement $M \& R$ expenditures has a greatly reduced reflex in reducing both the LCRUC and LCCCsc. It can also be seen that the majority of the non-dominated $M \& R$ strategies seem to be located in the steeper section of the Pareto front. The practical implication of this change in the trade-off relationships is that the highway agencies are presented with a greater number of potential solutions requiring a low level of pavement M\&R expenditure in which the money is likely to have a better marginal value than that corresponding to the solutions associated with a greater expenditure level. However, due to the deterioration of the strength of the relationships between the objectives observed for the heavier traffic class, the validity of the relationships previously described cannot be fully taken as guaranteed.

Tables 7 and 8 detail the features of the BOCSs chosen according to the methodology described in section 4.3 as well as the M\&R strategy defined by VDOT. Tables 9 and 10 present the variation of the LCHAC, LCRUC and LCCCsc for the BOCSs when compared to the current VDOT practice. These results are to be understood as follows: positive numbers mean that the BOCSs improve on VDOT practice, while negative numbers represent a deterioration of the metrics considered. According to the results presented in these tables, the selected optimal M\&R strategy improves on VDOT practice with regard to LCHAC, LCRUC and LCEI. The optimal M\&R strategy comprises six M\&R activities, five of which are scheduled to take place in the second half of the PAP when the traffic volume is more intense and the discounting factors present lower values. Another result of interest shown in Tables 7-10 is the fact that the reduction in the LCRUC and LCEI is achieved even though the optimal M\&R strategy leads to a slight reduction in the average pavement condition throughout the pavement life cycle. This is because in the optimal M\&R strategy five out of six M\&R activities are scheduled to take place in the second half of the PAP, whereas the VDOT practice consists of applying only three $M \& R$ activities in the same time period, thereby ensuring that the pavement is kept in good overall condition when the traffic is particularly intense.

When analysing the relevance of each pavement life cycle phase in the relative variation of the three metrics as a consequence of implementing the optimal M\&R plan, Tables 9 and 10 show that of the phases directly related to the highway agencies' responsibilities (i.e., materials extraction and production, M\&R and transportation of materials), the materials phase has the greatest influence in the decrease of the LCHAC. With regard to LCRUC, it can be seen that there is a reduction in the WZ RUC (approximately 29\%) and a small increase in the non-WZ RUC (approximately 1\%) when the best optimal compromise M\&R strategy is implemented in lieu of the current VDOT's M\&R strategy. However, the reductions in the LCRUC achieved through the implementation of the optimal M\&R strategy

outperform the increase in the costs occurred during the usage phase. Finally, the analysis of the variations of the LCCCsc allows us to come to a conclusion on the GHG emissions reductions that are expected to be obtained across all pavement life cycle phases when the optimal M\&R strategy is implemented. Such reductions are more substantial during the WZ traffic management (12\%) and materials (5\%) phases.

To provide an overall understanding of the relative importance of the pavement life cycle phases in the distribution of the costs and environmental impacts, the breakdown of the LCC and LCCCsc per pavement life cycle phase is provided in Fig. 3a and Fig. 3b, respectively. Fig. 3a shows that the LCRUC overwhelm the LCHAC, although the pavement life cycle phase that is responsible for the greatest share varies depending on the M\&R strategy considered. Specifically, in a maintenance scenario where the current VDOT practice is adopted, the majority of the LCRUC are incurred during the WZ traffic management phase ( $53 \%$ of total LCC), whereas the usage phase is more costly to road users when the optimal M\&R strategy is implemented. Regardless of the maintenance scenario adopted, the M\&R and transportation of materials remain the least costly life cycle phases $(47 \%$ of total LCC).

In terms of the LCCCsc, analysis of Fig. $3 b$ reveals that the cumulative effects of rolling resistance on fuel economy and vehicle emissions become much greater than the environmental burdens arising from the joint effect of the remaining phases, regardless of the maintenance scenario adopted ( $59 \%$ and $68 \%$ of total LCCCsc, respectively for the non-optimal and optimal M\&R strategy).

\subsubsection{Recycling-based maintenance and rehabilitation strategies}

Fig. 4 depicts the Pareto optimal set of solutions for the maintenance scenario where the M\&R activity of type RC combines conventional asphalt layers with in-place recycling layers. From this figure one can see that the Pareto front exhibits the same overall trend as that observed when the RC treatment consists of exclusively non-recycling-based asphalt layers (Fig. 2). More interestingly, this figure, when analysed in conjunction with Fig. 2, also shows that the entire Pareto front shifts down and towards the intersection of the LCHAC and LCRUC axis, resulting in significant costs and emissions savings across the pavement life cycle. This change will benefit both the highway agency and road users, with each seeing a decrease in the limits of the range of costs corresponding to the set of non-dominated solutions. Specifically, the lower and upper bounds of the LCHAC will respectively decrease by $29 \%$ and $14 \%$, whereas the road users are expected to experience more modest reductions in the incurred costs, which amount to $2 \%$ and $1 \%$, respectively, for the lower and upper boundaries. With regard to the range of GHG emissions, the lower and upper boundaries are likely to be reduced by $8 \%$ and $3 \%$, respectively.

Tables 11 and 12 detail the features of the best recycling-based optimal compromise M\&R strategies chosen according to the methodology described in section 4.3 as well as the M\&R strategy defined by VDOT, but in which no recycling-based M\&R activities are considered. Tables 13 and 14 present the variation of the LCHAC, LCRUC and LCCCsc for the BOCSs when compared to the current

Table 7

M\&R strategies of the best non-recycling-based optimal compromise solutions and current VDOT practice.

\begin{tabular}{|c|c|c|c|c|c|c|c|c|c|c|c|c|}
\hline Type of M\&R strategy & \multicolumn{10}{|c|}{ M\&R activity ID (application year) } & Average CCI & Average IRI \\
\hline Current VDOT practice & $4(7)$ & $5(17)$ & $6(27)$ & $4(39)$ & $5(49)$ & _- & _- & _- & _- & - & 82.74 & 1.27 \\
\hline
\end{tabular}

Legend: M\&R-maintenance and rehabilitation; CCI- critical condition index; IRI- international roughness index; VDOT- Virginia Department of Transportation. 
Table 8

Objective function values of the best non-recycling-based optimal compromise solutions and current VDOT practice.

\begin{tabular}{lllllll}
\hline $\begin{array}{l}\text { Type of M\&R } \\
\text { strategy }\end{array}$ & LCHAC $(\$)$ & $\operatorname{LCRUC}(\$)$ & $\begin{array}{l}\text { LCCCsc }(\mathrm{Kg} \\
\left.\mathrm{CO}_{2} \text {-eq }\right)\end{array}$ & $\mathrm{W}_{\mathrm{HAC}}$ & $\mathrm{W}_{\text {RUC }}$ & $\mathrm{W}_{\text {Env }}$ \\
\hline $\begin{array}{l}\text { Current } \\
\text { VDOT }\end{array}$ & $425,163.98$ & $2,665,172.68$ & $4,512,113$ & - & - & - \\
$\begin{array}{c}\text { practice } \\
\text { Optimal }\end{array}$ & $357,559.71$ & $1,925,908.77$ & $3,356,906$ & 0.8 & 0.1 & 0.1 \\
\hline
\end{tabular}

Legend: M\&R-maintenance and rehabilitation; VDOT- Virginia Department of Transportation; LCHAC- life cycle highway agency costs; LCRUC- life cycle road user costs; LCCCsc-life cycle climate change score; $\mathrm{W}_{\mathrm{HAC}^{-}}$weight assigned to the highway agency costs objective function; $\mathrm{W}_{\mathrm{RUC}}{ }^{-}$weight assigned to the road user costs objective function; $\mathrm{W}_{\mathrm{Env}}$-weight assigned to the environmental impacts objective function.

Table 9

Variation of the LCHAC and LCRUC for the non-recycling-based BOCS when compared to the current VDOT practice.

\begin{tabular}{llll}
\hline Stakeholder & Life cycle phase & \multicolumn{2}{l}{ LCC variation } \\
\hline & & Absolute $(\$)$ & Relative (\%) \\
\hline \multirow{2}{*}{ Highway agency } & Materials & $49,497.71$ & 11.64 \\
& M\&R & 7564.73 & 1.78 \\
& Transportation of Materials & $10,541.82$ & 2.48 \\
& Total & $67,604.27$ & 15.90 \\
Road Users & WZ Traffic Management & $768,696.39$ & 28.84 \\
& Usage & $-29,432.48$ & -1.10 \\
& Total & $739,263.91$ & 27.74 \\
& Total global & $806,868.18$ & 43.64 \\
\hline
\end{tabular}

Legend: LCHAC- life cycle highway agency costs; LCRUC- life cycle road user costs; BOCS- best optimal compromise solution; VDOT- Virginia Department of Transportation; M\&R-maintenance and rehabilitation; WZ-work zone.

Table 10

Variation of the LCCCsc for the best non-recycling-based optimal compromise solution when compared to the current VDOT practice.

\begin{tabular}{llll}
\hline Stakeholder & Life cycle phase & LCCCsc variation & \\
& & $\begin{array}{l}\text { Absolute }\left(\mathrm{Kg} \mathrm{CO}_{2}-\right. \\
\text { eq) }\end{array}$ & $\begin{array}{l}\text { Relative } \\
(\%)\end{array}$ \\
\hline $\begin{array}{l}\text { Highway } \\
\text { agency }\end{array}$ & Materials & 210,375 & 4.66 \\
& M\&R & 3661 & 0.08 \\
& Transportation of & 12,988 & 0.29 \\
Road Users & Materials & 562,000 & 12.46 \\
& WZ Traffic Management & 366,184 & 8.12 \\
& Usage & $1,155,207$ & 25.60 \\
\hline
\end{tabular}

Legend: LCCCsc-life cycle climate change score; VDOT- Virginia Department of Transportation; M\&R-maintenance and rehabilitation; WZ-work zone.
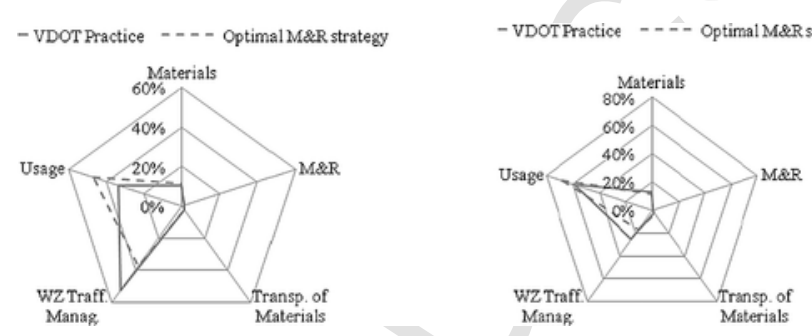

Fig. 3. Breakdown of the (a) LCC and (b) LCCCsc per pavement life cycle phase. Legend: M\&R-maintenance and rehabilitation; Transp. of Materials-transportation of materials; WZ-work zone.

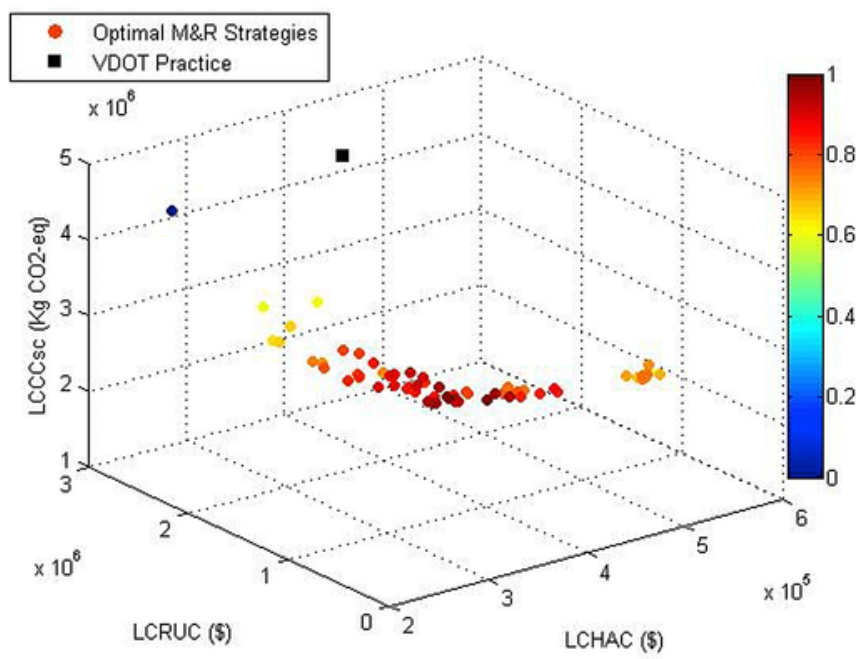

Fig. 4. M\&R strategy defined by VDOT and recycling-based Pareto optimal fronts Legend: LCHAC- life cycle highway agency costs; LCRUC- life cycle road user costs; LCCCsc-life cycle climate change score. Note: The fuzzy cardinal priority ranking of each non-dominated solution was normalized so that it falls into the range $[0 ; 1]$.

VDOT practice. As stated in the previous paragraph, Tables 12-14 show that, compared to the M\&R plan in current VDOT practice, both costs and GHG emissions are considerably lower for the best optimal compromise M\&R strategy. For instance, GHG emissions could be reduced by $45 \%$ and LCHAC and LCRUC by $13 \%$ and $59 \%$, respectively, if the highway agency switched the adopted M\&R strategy to the BOCS among those lying on the Pareto front.

An interesting analysis is to understand how the use of a recycling-based RC treatment changes the frequency and type of treatments integrating the optimal M\&R strategies, and how that translates into savings in both costs and GHG emissions. The results in Tables 11-14 show that the benefits are obtained by increasing the number of M\&R activities applied over the PAP (mainly PrM treatments), which translates into a smoother pavement surface over the PAP, thus reducing both the RUC and GHG emissions associated with the most important phase, i.e. the usage phase. Obviously, the increase in the frequency of $M \& R$ activities, without raising the expenditures incurred by the highway agency, was only possible because the recycling-based RC is cheaper than its non-recycling-based counterpart. Thereby, highway agencies are allowed to get more done with lower consumption of resources.

\subsection{Key findings}

From the results presented and thoroughly discussed in the previous section, the following findings are worth highlighting:

- In a tri-objective optimization analysis, minimizing LCHAC and LCCCsc are conflicting objectives, while LCRUC and LCCCsc denote the same trend;

- The Pareto front is better described as a cloud of points, meaning that highway agencies are presented with a greater variety of potential solutions within a narrow range of LCHAC values;

- The best compromise optimal M\&R strategy always improves on VDOT practice with regard to the three considered metrics;

- The LCRUC are considerably greater than the LCHAC, regardless of the type of M\&R strategy adopted;

- The usage phase is by far the most meaningful driver of the environmental performance of a road pavement section; 
Table 11

M\&R strategies of the best recycling-based optimal compromise solutions and current VDOT practice.

\begin{tabular}{|c|c|c|c|c|c|c|c|c|c|c|c|c|}
\hline \multirow[t]{2}{*}{ Type of M\&R strategy } & \multicolumn{10}{|c|}{ M\&R activity ID (application year) } & \multirow[t]{2}{*}{ Average CCI } & \multirow[t]{2}{*}{ Average IRI } \\
\hline & $1 \mathrm{st}$ & 2 nd & $3 \mathrm{rd}$ & 4 th & 5 th & 6 th & 7 th & 8th & 9th & 10th & & \\
\hline Current VDOT practice & $4(7)$ & $5(17)$ & $6(27)$ & $4(39)$ & $5(49)$ & - & - & - & - & - & 82.74 & 1.27 \\
\hline Recycling-based optimal & $2(2)$ & $4(4)$ & $3(12)$ & $4(18)$ & $7(24)$ & $4(30)$ & $3(36)$ & $4(41)$ & - & - & 80.76 & 1.11 \\
\hline
\end{tabular}

Legend: M\&R-maintenance and rehabilitation; CCI- critical condition index; IRI- international roughness index; VDOT- Virginia Department of Transportation.

Table 12

Objective functions values of the best recycling-based optimal compromise solutions and current VDOT practice.

\begin{tabular}{lllllll}
\hline $\begin{array}{l}\text { Type of M\&R } \\
\text { strategy }\end{array}$ & LCHAC $(\$)$ & LCRUC $(\$)$ & $\begin{array}{l}\text { LCCCsc }(\mathrm{Kg} \\
\left.\mathrm{CO}_{2} \text {-eq }\right)\end{array}$ & $\mathrm{W}_{\mathrm{HAC}}$ & $\mathrm{W}_{\mathrm{RUC}}$ & $\mathrm{W}_{\text {Env }}$ \\
\hline $\begin{array}{l}\text { Current VDOT } \\
\text { practice }\end{array}$ & $425,163.98$ & $2,665,172.68$ & $4,512,113$ & - & - & - \\
$\begin{array}{l}\text { Recycling- } \\
\text { based }\end{array}$ & $369,013.26$ & $1,083,439.83$ & $2,499,971$ & 0.2 & 0.8 & 0 \\
Optimal & & & & & & \\
\hline
\end{tabular}

Legend: M\&R-maintenance and rehabilitation; VDOT- Virginia Department of Transportation; LCHAC- life cycle highway agency costs; LCRUC- life cycle road user costs; LCCCsc-life cycle climate change score; $\mathrm{W}_{\mathrm{HAC}^{-}}$weight assigned to the highway agency costs objective function; $\mathrm{W}_{\mathrm{RUC}}{ }^{-}$weight assigned to the road user costs objective function; $\mathrm{W}_{\text {Env }}$-weight assigned to the environmental impacts objective function.

Table 13

Variation of the LCHAC and LCRUC for the best recycling-based optimal compromise solutions when compared to the current VDOT practice.

\begin{tabular}{llll}
\hline Stakeholder & Life cycle phase & LCC variation & \\
\hline & & Absolute $(\$)$ & Relative $(\%)$ \\
\hline Highway agency & Materials & $52,440.58$ & 12.33 \\
& M\&R & -7137.23 & -1.68 \\
& Transportation of Materials & $10,847.37$ & 2.55 \\
& Total & $56,150.72$ & 13.21 \\
Road Users & WZ Traffic Management & $1,160,552.62$ & 43.55 \\
& Usage & $421,180.23$ & 15.80 \\
& Total & $1,581,732.85$ & 59.35 \\
& Total global & $1,637,883.57$ & 72.56 \\
\hline
\end{tabular}

Legend: M\&R-maintenance and rehabilitation; Transp. of Materials-transportation of materials; WZ-work zone.

Table 14

Variation of the LCCCsc for the best recycling-based optimal compromise solutions when compared to the current VDOT practice.

\begin{tabular}{llll}
\hline Stakeholder & Life cycle phase & LCCCsc variation & \\
\hline & & Absolute $\left(\mathrm{Kg} \mathrm{CO}_{2^{-}}\right.$ & $\begin{array}{l}\text { Relative } \\
(\%)\end{array}$ \\
\hline eq) & 6.39 \\
Highway & Materials & 288,159 & -0.05 \\
& M\&R & -2304 & 0.54 \\
& Transportation of & 24,286 & 17.83 \\
Road Users & Materials & 804,717 & 19.89 \\
& WZ Traffic Management & 897,283 & 44.59
\end{tabular}

Legend: M\&R-maintenance and rehabilitation; Transp. of Materials-transportation of materials; WZ-work zone.
- The best recycling-based optimal compromise M\&R strategies always improve on VDOT practice with regard to the three considered metrics. Relatively speaking, an outstanding reduction of the LCRUC is observed, which can be up to approximately $60 \%$.

\section{Conclusions and future work}

This paper presents the development of a DSS framework for pavement management that has the ability to involve road users and environmental concerns, in addition to the highway agencies, in the road pavement maintenance decision making process, by comprehensively identifying and quantifying from a cradle-to-grave perspective the HAC, RUC and environmental impacts arisen throughout the pavement life cycle. Moreover, beyond the traditional economic objective (i.e., minimization of HAC), it enables environmental and road user-related objectives to be jointly optimized by employing a tri-objective optimization procedure to generate a set of potentially optimal pavement M\&R strategies for a road pavement section while satisfying multiple constraints. Finally, the capabilities of the presented framework are enhanced by including a decision-support module that provides the DM with the BOCS among those lying on the Pareto front.

The capabilities of the proposed DSS were demonstrated by mean of a case study consisting of determining the optimal M\&R strategy for a high-volume traffic road flexible pavement section of a typical Interstate highway in Virginia, US. The MOO results revealed the existence of conflict between the LCHAC and LCRUC and between LCHAC and LCCCsc, whereby an increase in one of the objectives leads to a decrease in the other. In turn, LCRUC and LCCCsc were found to follow the same trend since an increase in one metric is accompanied by an increase in the other. Furthermore, to assess the strength of relationships between the objective functions previously described, Spearman's correlation analysis was performed along with significant tests of correlation coefficients. The results of the analysis not only demonstrate that the relationships are at least strong but also that they are backed up statistically.

The results of this case study also indicate that the best optimal compromise M\&R plan has the potential to improve on current VDOT's pavement M\&R practice with regard to the three considered metrics. Specifically, reductions of approximately $16 \%, 28 \%$ and $26 \%$ in the LCHAC, LCRUC and LCCCsc. can be achieved if the M\&R plan corresponding to the BOCS is adopted instead of that currently adopted by VDOT.

Furthermore, in order to assess the extent to which new pavement engineering solutions can potentially enhance pavement sustainability, a complementary analysis scenario was performed in which the most structurally robust M\&R activity initially considered was replaced by an equivalent recycling-based M\&R activity. The results of this analysis showed that not only reductions in all three considered metrics can be achieved by moving from the current pavement $M \& R$ practice to the best recycling-based optimal compromise M\&R strategy but also that such reductions can almost double those observed in the first scenario for the LCRUC and LCCCsc. metrics, while the 
LCHAC reductions were found to be roughly the same in both scenarios.

The optimization-based DSS presented in this paper proved to be efficient in the incorporation of environmental and road user-related considerations in the sustainable decision-making process of pavement management. Compared to the existing SOO models or even the bi-objective optimization models, the proposed model combines the desirability of simultaneously accounting for several lifetime metrics of sustainability, while also providing the possibility of visualizing, and thereby understanding more deeply their relationships and eventual trade-offs.

In the near future, the development of this DSS will proceed in two main directions. First, the decision level for which the current version is intended for will be upgraded from the project level to the network level to ensure that the road pavement maintenance decisions taken at project level end up in optimal sustainable solutions for the whole road pavement network. Second, the number of LCA-based metrics allowed to be simultaneously optimized with highway agencies and road user-related objectives will be extended. In an effort to overcome the computational limitations associated with solving many-objective optimization (MaOO) problems, the use of dimensionality reduction techniques in improving the efficiency and efficacy of the current DSS's solution algorithm when applied to solve $\mathrm{MaOO}$ problems will be assessed. If the applicability of those techniques to the pavement management problems is found to be successful, they will become the $\mathrm{MaOO}$ problems computationally tractable by identifying redundant objectives that can be omitted while still preserving the problem structure as far as possible.

\section{Uncited reference}

EAPA, 2016.

\section{Acknowledgements and disclaimer}

This work has been supported by the project PAVENERGY Pavement Energy Harvest Solutions (PTDC/ECM-TRA/3423/2014), co-financed by the European Regional Development Fund (ERDF) through the Operational Programme for Competitiveness Factors (COMPETE) and by national funds through the Portuguese Foundation for Science and Technology (FCT), and also by the Transportation Pooled Fund TPF-5(268) National Sustainable Pavement Consortium. João Santos wishes to thank the Portuguese Foundation for Science and Technology for a personal research grant (SFRH/BD/79982/2011). The contents of this paper reflect the views of the authors, who are responsible for the facts and the accuracy of the data presented. The contents do not necessarily reflect the official views or policies of the Virginia Department of Transportation, the Commonwealth Transportation Board or the Federal Highway Administration. Any inclusion of manufacturer names, trade names, or trademarks is for identification purposes only and is not to be considered an endorsement. Moreover, this paper does not constitute a standard, specification, or regulation.

\section{References}

Aurangzeb, Q., Al-Qadi, I.L., Ozer, H., Yang, R., 2014. Hybrid life cycle assessment for asphalt mixtures with high RAP content. Resour. Conserv. Recycl 83, 77-86. http://dx.doi.org/10.1016/j.resconrec.2013.12.004.

Bare, J., 2011. TRACI 2.0: the tool for the reduction and assessment of chemical and other environmental impacts 2.0. J. Clean Techn Environ Policy 13, 687-696. http: //dx.doi.org/10.1007/s10098-010-0338-9.

Bryce, J.M., Flintsch, G., Hall, R.P., 2014. A multi criteria decision analysis technique for including environmental impacts in sustainable infrastructure management business practices. Transp. Res. Part Transp. Environ. 32, 435-445. http://dx.doi. org/10.1016/j.trd.2014.08.019.

Carnegie Mellon University Green Design Institute, 2010. Economic Input-output Life Cycle Assessment (EIO-lca), U.S. 2002, Industry Benchmark model.

Chowdhury, T., 2011. Supporting Document for the Development and Enhancement of the Pavement Maintenance Decision Matrices Used in the Needs-based Analysis. Virginia Department of Transportation, Maintenance Division, Richmond, VA, USA.

Därcher, K., Gorski, J., Klamroth, K., 2012. An augmented weighted Tchebycheff method with adaptively chosen parameters for discrete bicriteria optimization problems. Comp. Oper. Res. 39, 2929-2943. http://dx.doi.org/10.1016/j.cor.2012. 02.021 .

Diefenderfer, B., Apeagyei, A., 2014. I-81 In-place Pavement Recycling Project (Report No. FHWA/VCTIR 15-R1). Virginia Center for Transportation Innovation and Research, Charlottesville, VA, USA.

Ducasse, K., Distin, T., Osborne, L., 2004. The use of microsurfacing as a cost effective remedial action for surface rutting. In: Proceedings of the 8th Conference on Asphalt Pavements for Southern Africa, Sun City, South Africa.

EAPA (European Asphalt Pavement Association), 2016. EUPAVE (European Concrete Paving Association), FEHRL (Forum of European National Highway Research Laboratories), Road pavement industries highlight huge $\mathrm{CO}^{2}$ savings offered by maintaining and upgrading roads.

Ehrgott, M., Gandibleux, X., 2004. Approximative solution methods for combinatorial multicriteria optimization. TOP 12, 1-88. http://dx.doi.org/10.1007/BF02578918.

Ferreira, A., Picado-Santos, L., Antunes, A., 2002. A segment-linked optimization model for deterministic pavement management systems. Int. J. Pavement Eng. 3, 95-105. http://dx.doi.org/10.1080/10298430290030603.

Harvey, J., Kendall, A., Lee, I.-S., Santero, N., Van Dam, T., Wang, T., 2010. Pavement Life Cycle Assessment Workshop: Discussion Summary and Guidelines (Technical Memorandum: UCPRC-tm-2010-03). Pavement Research Center, University of California, Davis, California, USA.

International Panel on Climate Change (IPCC), 2007. Climate change 2007: the physical science basis. Contribution of working group I to the fourth assessment report of the intergovernmental Panel on climate change. In: Solomon, Qin, S., Manning, M., Chen, Z., Marquis, M., Averyt, K.B., Tignor, M., Miller, H.L. (Eds.). Cambridge University Press, Cambridge, UK and New York, USA, pp. 1-996.

International Standard Organization (ISO), 2006a. ISO 14040: 2006. International Standard ISO 14040: Environmental Management - Life Cycle Assessment: Principles and Framework, October. Geneva (Switzerland). International Organization for Standardization.

International Standard Organization (ISO), 2006b. ISO 14044:2006. International Standard ISO 14044: Environmental Management - Life Cycle Assessment: Requirements and Guidelines, October. Geneva (Switzerland). International Organization for Standardization.

Keoleian, G.A., Spitzley, D.V., 2006. Life cycle based sustainability metrics. In: Abraham, M.A. (Ed.), Sustainability Science and Engineering: Defining Principles (Sustainability Science and Engineering, Volume 1). Elsevier B. V., Amsterdam, The Netherlands, pp. 127-159.

Lee, J., Madanat, S., Reger, D., 2016. Pavement systems reconstruction and resurfacing policies for minimization of life-cycle costs under greenhouse gas emissions constraints. Transp. Res. Part. Method 93 (Part A), 618-630. http://dx.doi.org/10. 1016/j.trb.2016.08.016

Lidicker, J., Sathaye, N., Madanat, S., Horvath, A., 2013. Pavement resurfacing policy for minimization of life-cycle costs and greenhouse gas emissions. J. Infrastruct. Syst. 19, 129-137. http://dx.doi.org/10.1061/(ASCE)IS.1943-555X.0000114.

Machin, D., Cambpell, M.J., Walters, S.J., 2007. Medical Statistics: a Textbook for Health Sciences, fourth ed. John Wiley \& Sons Ltd, West Sussex, UK

Marler, R.T., Arora, J.S., 2004. Survey of multi-objective optimization methods for engineering. Struct. Multidiscip. Optim. 26, 369-395. http://dx.doi.org/10.1007/ s00158-003-0368-6.

MATLAB, 2015. MATLAB Primer, Version 8.5. The MathWorks Inc., Natick, Massachusetts, USA.

Miettinen, K.M., 1999. Nonlinear Multiobjective Optimization. Kluwer Academic Publishers, Boston.

OMB (Office of Management and Budget), 2013. Discount Rates for Cost-effectiveness, Lease Purchase, and Related Analyses. Table of past years discount rates from Appendix C of OMB Circular No. A-94 http://www.whitehouse.gov/omb/ circulars_a094/a94_appx-c, (Accessed October 2016).

Santero, N., Horvath, A., 2009. Global warming potential of pavements. Environ. Res. Lett. 4, 1-7. http://dx.doi.org/10.1088/1748-9326/4/3/034011.

Santero, N., Masanet, E., Horvath, A., 2011. Life-cycle assessment of pavements. Part I: critical review. Resour. Conserv. Recycl 55, 801-809. http://dx.doi.org/10.1016/ j.resconrec.2011.03.010

Santos, J., Ferreira, A., Flintsch, G., 2017a. An adaptive hybrid genetic algorithm for pavement management. Int. J. Pavement Eng. http://dx.doi.org/10.1080/10298436. 2017.1293260 . 
Santos, J., Flintsch, G., Ferreira, A., 2017b. Environmental and economic assessment of pavement construction and management practices for enhancing pavement sustainability. Resour. Conserv. Recycl 116, 15-31. http://dx.doi.org/10.1016/j. resconrec.2016.08.025.

Santos, J., Ferreira, A., Flintsch, G., 2015a. A life cycle assessment model for pavement management: methodology and computational framework. Int. J. Pavement Eng. 16, 268-286. http://dx.doi.org/10.1080/10298436.2014.942861.

Santos, J., Bryce, J.M., Flintsch, G., Ferreira, A., Diefenderfer, B., 2015b. A life cycle assessment of in-place recycling and conventional pavement construction and maintenance practices. Struct. Infrastruct. Eng. Maint. Manag. Life Cycle Des. Perform. 11, 119-1217. http://dx.doi.org/10.1080/15732479.2014.945095.

Santos, J., Bryce, J.M., Flintsch, G., Ferreira, A., 2015c. A comprehensive life cycle costs analysis of in-place recycling and conventional pavement construction and maintenance practices. Int. J. Pavement Eng. http://dx.doi.org/10.1080/10298436. 2015.1122190.

Stantec Consulting Services, Lochner, H., 2007. Development of Performance Prediction Models for Virginia Department of Transportation Pavement Management System. Virginia Department of Transportation, Richmond, VA, USA.

Steuer, R.E., 1986. Multiple Criteria Optimization: Theory, Computation and Application. John Wiley \& Sons, Inc., NewYork.

Swarr, T., Hunkeler, D., Klöpffer, W., Pesonen, H.-L., Ciroth, A., Brent, A., Pagan, R 2011. In: Environmental Life Cycle Costing: a Code of Practice. Society of Environmental Chemistry and Toxicology (SETAC), Pensacola (FL).

Talbi, E.-G., 2009. Metaheuristics: from Design to Implementation. John Wiley \& Sons, Inc., New Jersey.

Torres-Machi, C., Pellicer, E., Yepes, V., Chamorro, A., 2017. Towards a sustainable optimization of pavement maintenance programs under budgetary restrictions. J. Clean. Prod. 148, 90-102. http://dx.doi.org/10.1016/j.jclepro.2017.01.100.

VDOT (Virginia Department of Transportation), 2014. Manual of Instructions for the Materials Division. Virginia Department of Transportation Materials Division, VA, USA.
VDOT (Virginia Department of Transportation), 2013. Project Selection Guidelines for Cold Pavement Recycling. Virginia Department of Transportation Materials Division, VA, USA.

VDOT (Virginia Department of Transportation), 2012. Construction Resources Guidebook, Division II- Materials, Special Provision Copied Notes (SPCNs), Special Provision (SPs) and Supplemental Specifications (Ss), Updated July 8, 2014. Virginia Department of Transportation Construction Division, Central Office, Richmond, VA, USA.

Walls, J., Smith, M., 1998. Life-cycle Cost Analysis in Pavement Design - in Search of Better Investment Decisions (Report No. FHWA-SA-98-079). Federal Highway Administration, Washington, D.C., USA.

Wu, Z., Flintsch, G., 2009. Pavement preservation optimization considering multiple objectives and budget variability. J. Transp. Eng. 135, 305-315. http://dx.doi.org/ 10.1061/(ASCE)TE.1943-5436.0000006.

Wu, Z., Flintsch, G., Ferreira, A., Picado-Santos, L., 2012. Framework for multiobjective optimization of physical highway assets investments. J. Transp. Eng. 138, 1411-1421. http://dx.doi.org/10.1061/(ASCE)TE.1943-5436.0000458.

Yu, B., Gu, X., Ni, F., Guo, R., 2015. Multi-objective optimization for asphalt pavement maintenance plans at project level: integrating performance, cost and environment. Transp. Res. Part Transp. Environ. 41, 64-74. http://dx.doi.org/10.1016/j. $\operatorname{trd} .2015 .09 .016$.

Zhang, H., Keoleian, G.A., Lepech, M.D., Kendall, A., 2010. Life-cycle optimization of pavement overlay systems. J. Infrastruct. Syst. 16, 310-322. http://dx.doi.org/ 10.1061/(ASCE)IS.1943-555X.0000042.

Zimmormann, H., 1996. Fuzzy Set Theory- and its Application, third ed. Kluwer Academic Publishers, Norwell.

Zou, K.H., Tuncall, K., Silverman, S.G., 2003. Correlation and simple linear regression. Radiology 227, 617-628. http://dx.doi.org/10.1148/radiol.2273011499. 